\title{
Movie Subtitle Translation: Relevance Theory Perspective with Reference to the Movie The Shawshank Redemption as the Case Study
}

\author{
Li Xinya \\ Department of Foreign Languages, Tianjin University of Finance and Economics, Tianjin, China
}

Email address:

beckaa1234@163.com

\section{To cite this article:}

Li Xinya. Movie Subtitle Translation: Relevance Theory Perspective with Reference to the Movie The Shawshank Redemption as the Case Study. International Journal of Language and Linguistics. Vol. 4, No. 2, 2016, pp. 61-69. doi: 10.11648/j.ij11.20160402.13

\begin{abstract}
This paper aims at exploring the efficient strategies of movie-subtitle translation by analyzing the problems in the translating process in terms of linguistic and cultural obstructions. By evaluating the English-Chinese translated version of the film The Shawshank Redemption, a 1994 American drama released by the Time Warner Company ${ }^{1}$, the author tries to show how relevance theory works in dealing with the problems in translation, namely cultural differences, word games, style and omission in translation. Relevance theory is powerful and efficient in overcoming linguistic, cultural and stylistic obstacles in translation process. It allows translators more freedom to recreate their own translation versions rather than being trapped in the "meaning and form" dilemma as (translation) is supposed to "render the meaning of a text into another language in the way that the author intended the text" (Newmark, 2001: 5). This is especially true in the movie subtitle translation due to its unique features as a text and the expectation from the audiences.
\end{abstract}

Keywords: Relevance Theory, Subtitle, Contextual Effects, Assumptions

\section{Introduction}

Nowadays Hollywood movies with Chinese subtitles become a commonplace in Chinese entertainment industry. Floods of western films together with consumers' urgent demand to watch the newly-released movies make dubbed films unprofitable and impossible. Under this circumstance, Chinese subtitles are very crucial to the production of films for the Chinese audience. However, as a cultural product of foreign countries, films' intended effects are not confined to visual and audio effects. The differences in languages, namely the pronunciation, grammar, vocabulary, idiomatic expressions, rules of conversation and writing, gender and more often confuse us (Behrens \& Parker, 2010: 31). Researchers have devoted efforts to approach these issues from an academic perspective. The translation strategies and skills have been elaborated; translation theories and theories from other fields have been borrowed in the exploration of the translation process of film subtitles. The individual research on translators is also conducted. Intra-lingual (within the same language) and inter-lingual (between different languages) translation, the entertained rewriting in the film subtitle translation are some of the academic focus (Zheng, 2011: 75-78) (Lv Yuyong, Li Min, 2013: 105-109). As clearly shown from these findings, it is not possible to come up with the standardized strategies to be adopted in film subtitle translation. Therefore, the author approaches this film from the relevant theory with a concrete case study followed in the hope to reveal part of the complicities of film subtitle translation.

\section{Relevant Theory and Movie Subtitles}

It is often the case that we grasp the main parts of the movie with a few unsolved questions through watching the movie. What are the deep-rooted causes behind problems and how to avoid them or reduce their occurrences at least? To find the answers for these questions would be very helpful for improving the effect of the communication. It is reasonable to suppose that translators must have been confused at the long-lasting paradox of "form and meanings". According to Bell (2003: 7).

The translator has the option, then, of focusing on finding formal equivalents which 'preserve' the context free semantic sense of the text at the expense of its context sensitive 
communicative value or finding functional equivalents which 'preserve' the context-sensitive communication value of the text at the expense of its context-free semantic sense.

How to strike a delicate balance between form and meaning in the movie translation? The author shall explore this issue by analyzing problems in the English-Chinese subtitle translation of the movie The Shawshank Redemption under relevance theory framework.

A general introduction of relevance theory and the features of film subtitles shall be presented as the starting point of the discussion.

\subsection{Relevance Theory in Gutt's Cognitive Approach to Translation}

The relevance theory, adopted by Ernst-August Gutt in his cognitive approach to translation, is a theory raised by Sperber and Wilson (2001) on the critical analysis of Grice's theory of conversation. They reveal an important cognitive assumption that people are apt to stick to the economical principle in communication. In other words, relevance theory explains the communication from speakers' and hearers' perspectives. Speakers should produce correct assumptions to lead hearers to their intended meanings with no-extra efforts. On the other side, the hearer is expected to process the handiest information until the information gives him/her adequate contextual effect to make the speaker's utterance reasonable. That is the mechanism working in the interactions among people.

\subsection{Translation Defined in Relevance Theory}

The definition of translation has been the topic of continued discussion in the academic world. However, there is no unanimous agreement about translation. Translation, under relevance theory framework, is an outcome aimed at achieving the similar explicatures and implicatures of the original text. As for inter-lingual translation, there are two main tasks to be fulfilled, namely, language barrier and problems aroused by different cognitive circumstances (Hickey, 2001: 49). These are vital for translation success. In the light of relevance theory, translation is a form of communication. The main difference between translation and daily communication is the fact that translators have two-facet roles. They are hearers to the source-language writer while speakers to the target-language audience. They, in the first stage, find the author-intended meanings by processing their storage of knowledge and then make every effort to ensure that the target language audiences draw the source-language author-intended meanings without extra efforts. Both the two roles are operated under the mechanism of relevance theory, which "heavily constrains the translation with regard to both what it is intended to convey and how it is expressed" (Gutt, 2004: 107).

\subsection{Characteristics of Screenwriting}

The characteristics of spoken language could be applied to screenwriting pieces which are a type of spoken language. They have been summarized as following, "the syntax of spoken language is typically much less structured than that of written language; The speaker is typically less explicit than the writer; the speaker typically uses a good deal of rather generalized vocabulary; the speaker may produce a large number of prefabricated 'fillers'..." (Brown, G. \& George Yule, 1983: 15-17). To be more specific, just as Dick (1990: 192-193) describes "the ideal screenplay advances the plot in two ways: verbally, through dialogue, and visually, through action. When the visual might be more effective than the verbal, the writer must suppress the desire to rely on dialogue..." Economy is an essential motif of screenwriting. Therefore "screen dialogue is often truncated-that is, sentences are frequently left unfinished, and speech is fragmentary. Thus, screen language is closer to actual conversation than any other kind of dialogue."

\subsection{Characteristics of Movie Subtitles}

Most subtitles are translated from screen scripts. Therefore, subtitles maintain many of the features of screen dialogues, which often fall into spoken catalogue. Spoken language is always employed in everyday talks and narration. Spoken language is demotic and vivid. "It is short and less than 10 words in one sentence in most cases" (Lv, 2004: 52). Subtitles fall into two parts-intra-lingual and inter-lingual. "Inter-lingual subtitles carry three meanings, namely, the delivery of inter-lingual messages, the simplification or condensation of text and the transition from spoken to formal version" (Luyken et al, 1991). The subtitle tends to employ common words and phrases. As Asher, R. E. \& M. Y. Simpson (1994) said: "subtitles were to be present only when leaving them out would harm the story."

\section{Application of Relevance Theory in the Translation of the Movie The Shawshank Redemption}

As a routine, once assigned to a translation task, translators will page through the text to get the analysis and assessment of the text, the basis of their translation strategies. The analysis and assessment of a text is the first step of translation. It includes "the intention of the text, the intention of the translator, text styles, the readership, stylistic scales, attitudes, and setting..." (Newmark, 2001: 12-15). Falling into the category of literature translation, subtitle translation should resemble feelings and emphasize the artistic style and visual-audio effects. (Wang, 2002: 331). The movie The Shawshank Redemption (1994) is an impressive drama from director and screenwriter Frank Darabont who adapts Stephen King's novel of the same name. It is an enlightening movie inspiring us to reflect life and real self. In 2015, the United States Library of Congress selected the film for preservation in the National Film Registry, finding it "culturally, historically, or aesthetically significant" (Morgan, 2015: 12). It, as its name shows, illustrates the liberating and redemptive power of hope and the religious themes of freedom and resurrection. "Fear can hold you prisoner, hope can set you free." It is a movie exploring everyday colloquial, slang and 
taboo in an effort to present Chinese audience a real and vivid picture of prisoners' lives. However, the analysis of text itself is not sufficient enough to achieve the effects mentioned above by Mr. Wang. Cultural and linguistic differences hinder translators' role of being "speakers to the target-language audience", namely linguistic structure obstruction, expression obstruction, semantic obstruction and cultural obstruction, which are summed up in cultural and stylistic issues (Liu, 2003: 130). Confronted with the obstructions, translators have to explore ways to render the message of the SL text without demanding extra efforts from the TL audience.

\subsection{Methods Adopted to Narrow Cultural Differences}

Translation is not new in the development of human beings. Whenever communication is blocked, translating process is needed. Even in China we sometimes have to translate, from ancient Chinese to current Chinese, from dialects to mandarin. Inter-lingual translation is more difficult because you have to inform audience with totally different backgrounds. Translators are required to interpret the original speeches in the secondary communication, in which the cognitive environment is not the same envisioned by the original audience (Hickey, 2001: 49). In most cases, translator has to explain these items, add extra notes to it or omit it. Translators' strategies varies depend on the nature of the issues.

\subsubsection{No Cultural Counterpart Exists}

Language reflects features of certain historical and geographic circumstances. It is no wonder that there is no counterpart in target language. It might be a concept, a tangible item and even different attitudes and feelings about the same item. This is very common in movie subtitle translation. The following is a typical example from the movie The Shawshank Redemption.

Example 1.

Andy Dufresne, a vice-president of a large Portland bank, is accused of having murdered his wife and her lover after he found out the disloyalty of his wife. The movie starts with the accusation of the interrogation of a defendant in the courtroom.

D. A. (O. S.): Mr. Dufresne, describe the confrontation you had with your wife the night she was murdered.

ANDY: It was very bitter. She said she was glad I knew, that she hated all the sneaking around. She said she wanted a divorce in Reno.

D. A.: What was your response?

ANDY: I told her I would not grant one.

D. A.: (refers to his notes) I'll see you in Hell before I see you in Reno. Those were the words you used, Mr. Dufresne, according to the testimony of your neighbors.

ANDY: If they say so. I really don't remember. I was upset.

As quoted above, the defendant and Andy use formal words in conversation in the courtroom, such as "confrontation, grant and the testimony". "Confrontation is a dispute, fight, or battle between two groups of people, which is not proper in daily life" (Collins Cobuild English Dictionary, 1999: 340). The use of formal words makes the authentic and superior nature of law honored in the courtroom. Besides, marriage is holy in America. Minister declares that "those, whom God has joined together, let no man put asunder. In so much as the (Groom's Name) and the (Bride's Name) have consented together in holy wedlock, and have witnessed the same before God and this company..." (pronouncement of marriage). Therefore, any American audience will see what the two characters say natural. However, if a translator uses formal words in Chinese version to maintain the formal atmosphere, Chinese audience might be a little uncomfortable. Generally speaking, divorce has nothing to do with religion for ordinary Chinese. Even in the courtroom the two sides don't need to use too formal words. In other words, these formal expressions are not relevant to Chinese audience if they have no idea of the specific background. Courtroom and marriage have different meanings to Chinese and Americans, in terms of mental activities, ritual behaviors and among other things, since "culture is that complex whole which includes knowledge, belief, art, morals, law, customs and any other capabilities and habits acquired by man as a member of group" (Katan, 2004: 16 as quoted from Tylor, 1871).

Another example is that Andy says, "She said she wanted a divorce in Reno." If the translator puts it literally, Chinese audience might treat it as Andy's wife's provision-she wants to get divorce in a place called Reno. But a reference on the internet will show you "By 1909, Reno had earned the title of "the nation's new divorce headquarters." The generous number of grounds available to divorce-seekers in Nevada in addition to its relatively short residency period - six months, at the time - set it apart" (Reno divorce history). With this background in mind, it makes sense to see Andy's wife pack her things and live with her lover. But the problem is that there is no such a place like Reno in China. The translator may think Reno is too important to be omitted. Then he/she can either add extra notes or explain it in the screen dialogue. However, for movie-watchers, adding notes is impossible and explaining in dialogues is ridiculous in this case. Therefore, its Chinese version is "She said she demanded a divorce". The translator here omits the item but explicits her real meaning. It seems to fail to convey all the information behind this expression. However, in term of relevance theory, both speakers and listeners aim at optimal relevance - getting adequate contextual effects at minimal efforts not maximal effects. In any text the whole contextual effects are too enormous to gain. Adequate contextual effects make what the speaker said reasonable to the hearer. After consulting their logical entries, lexical entries and encyclopaedic entries, American audience knows that Andy's wife wants to divorce him. It is the same with its Chinese version. Both the American and Chinese audiences get the same effects but with various efforts. Besides, to interpret it correctly, Chinese audience consult their definition of "divorce" while the original audience has to consult their encyclopaedic entries which demands more mental cost. After the translator's simplification of the information, the relevance becomes higher than its English version, for the less efforts cost, the higher the relevance is. Chinese and English versions achieve different relevance. But 
both Americans and Chinese get adequate contextual effects. This strategy is a ready choice of translators when there is no cultural counterpart in target language.

\subsubsection{Chinese Courtparts Available}

People in different countries have the basically similar needs and they live in similar circumstances. It is not hard to find counterparts of SL expressions in target language, which makes translation relatively more easily. The following is a typical example in The Shawshank Redemption.

Example 2.

HADLEY: I ain't gonna count to three! Not even to one! Now shut the fuck up 'fore I sing you a lullabye! ...If I hear so much as a mouse fart in here the rest of the night, by God and Sonny Jesus, you'll all visit the infirmary.

This scene occurs when some new prisoners spend their first day in prison. One of them is so scared that he keeps crying. This makes Hadley, an official, rather angry. Hadley is threatening here. If there was any sound, they would be beaten badly. God would be his witness. He means what he said. However, the literal version seems rather unnatural to Chinese audience. So the translator changes it as "Shut your mouth without further warnings. Otherwise you shall face the consequence! If any sound was heard in the evening, I swear to the Heaven, I'll make you sorry for it. Nobody shall be let off." Here the translator explores quite colloquial Chinese idioms. "by God and Sonny Jesus" is replaced by "swear to the Heaven" while "you'll all visit the infirmary" is replaced by "make you feel sorry for it". By consulting their own encyclopaedic entries, Chinese audience get their efforts rewarded. "Swear to the Heaven" and "make you feel sorry for it" always convey a threatening and vulgar tone of the speaker to Chinese audience. The use of short sentences makes Chinese audience sense the cruelty of Hadley.

\subsubsection{Cultural Items with Little Information Known to the Target Audience}

The treatment of cultural items with little information known to the target audience is not the same as the words of which the Chinese have no idea. With increasing exchanges, some cultural items such as the Bible, FBI, and the White House are not completely unknown to Chinese audience. For example,

Example 3.

NORTON: I'm pleased to see you reading this. Any favorite passages?

ANDY: Watch ye therefore, for ye know not when the master of the house cometh.

NORTON: (smiles) Mark. Chapter 13, verse 35. I've always liked that one. (strolls the cell) But I prefer: "I am the light of the world. He that followeth me shall not walk in darkness, but shall have the light of life."

ANDY: John. Chapter 8, verse 12.

NORTON: I hear you're good with numbers. How nice. A man should have a skill.

As mentioned above, the Bible is not a totally new item to Chinese audience. It is a shared item about Christianity to Americans and Chinese. But it has different implications to them. The scripter choosing the Bible might be because The Shawshank Redemption is a movie about survival and the redemption. In this scene the shared zest for the Bible between Andy and Norton convinced the latter that Andy is reliable. Therefore the translator is expected to translate the verses while preserving Biblical style. Translators can achieve this effect by consulting the Bible's Chinese version. Cultural items of this catalogue are relatively easy to translate for there is an established form to consult. In some extent, their Chinese versions introduce these items to the Chinese. These cultural items have become a part of their shared cognitive environment.

How to deal with items with cultural implications is a dilemma for translators. If they deliver the meaning of a cultural item with the cultural image omitted, they might be criticized for not introducing foreign cultural items. If they do preserve the form of the cultural items, "Reno" for example, then it does not make sense or is misleading. However, relevance theory has its own solution. If target audience can get adequate contextual effects from the utterance without knowing exactly what the cultural items are, then the cultural items can be omitted. If the cultural items are crucial to the delivery of the tone and assumptions of utterance, then seeking a courtpart in target language is a choice. Otherwise the omission of such words will fail to offer adequate context effects, which leads to the failure of communication.

\subsection{Word Games}

"Any game or contest involving skill in using, forming, guessing, or changing words or expressions, such as anagrams or Scrabble" are word games. Movie is a form of art representing itself via language and action. So it is not hard to find word-games in movie. Word games are hard to be represented in inter-lingual communication for their unique phonetic, word formation and sentence patterns. For example,

Example 4.

Andy's newly made friends in Shawshrank prison decide to collect some useful stones for him as a welcome back from the infirmary. But the problem is that they have little knowledge of rocks. When Heywood finds out a "fit rock" in the exercise yard, he is eager to share with other prisoners. Once told the rock he picked is not what it seems like, he is irritated.

HEYWOOD: What the hell is it then?

RED: Horse apple.

HEYWOOD: Bullshit.

RED: No, horse shit. Petrified.

People with a little knowledge of English will notice the word-game in this short talk. Horse apple is a new word. When come across in other places, even the native speakers might not be sure what it refers to. But it is easy to understand its meaning - the ordure of horse. With the image of apple in our minds, we are likely to feel disgusted. "When you say that something is bullshit, you are saying that it is nonsense or completely untrue; an informal use which some people find offensive" (Collins Cobuild English Dictionary: 213). At hearing this, Red utters "No, horse shit. Petrified.", which stirs a loud laughter. If translated literally, it is easy to see that the 
fun brought out by the word-game is lost. In this sense, the efforts of Chinese audience in processing the information are not rewarded. They cannot appreciate the fun in this word-game. It shows that it is almost impossible to let the target audience understand the fun by preserving the form the source language. It, in some extent, shows that word games are untranslatable. But it doesn't mean that word games cannot be appreciated by target language audience. Instead of imitation of the structure and wordings of original text, translators should achieve relevance of their own.

Films are normally the real reflection of our life. Word games centered on the effect resulting from the syntax and phonetic differences are commonplace in films. They give films real and special touch. Some translators choose to ignore the effects while some attempt to achieve the effects. There are continued discussions on this issue. In my opinion, the latter one is better since the audience efforts should be rewarded and the characters' reactions in the screen can be explained by offering the similar effects. Otherwise, as in the Example 3, Chinese audience will be confused at the laughter.

\subsection{Maintenance of the Style in the Shawshank Redemption}

According to relevance theory, "the assessment of relevance, like the assessment of productivity, is a matter of balancing output against input: here contextual effects against processing effort" (Sperber \& Wilson, 2003: 125). However, that does not mean explicating all the implications in the original text. People aim at adequate not maximum contextual effects. How the text is presented and the formation of words and texts are very important. They offer more information about the characters, the theme and the effects. In short, the style of the text is important in portraying characters and serving the theme. Translators cannot ignore it. We can get the clue of speakers' different backgrounds by their choice of words. The general style of a text is manifested by "the wording tendency, sentence features, rhetoric and sentence patterns (negative, rhetorical, direct and indirect) " (Liu, 1998: 577-578) and "the style of a text is an important factor in stirring similar effects on target audience" (Jin, 1998: 49).

\subsubsection{Indirectness}

The movie has many indirect speeches. They serve the theme perfectly and make the film more meaningful. The main difference between direct and indirect speeches is elaborated as followed. Directness strengthens a particular assumption of the hearer's, so it explicates the meanings. Whereas indirectness "encourages the hearer to look for a range of further contextual implications not shared, not equally strengthened, ... and assume that within this range there are some he intends to implicate" (Sperber \&Wilson, 2003: 235). That is to say, the contextual effects of direct and indirect discourses are different. Directness brings out more contextual effects. For example,

Example 5.

Never seen such a sorry-lookin' heap of maggot shit in my life.

Get this tub of shit down to the infirmary.

Who's your horse?

You're a cold fish.

In this catalogue, people are presented by various kinds of images in accordance with their communicative intentions. Prisoners are referred as "heap of maggot" and "tub of shit". Their Chinese versions are "Never in my life seen such a bad person" "Carry him to the treatment room". By comparing these two versions, we will find the derogatory sense of the original expressions is lost during the translation. Chinese audience probably thinks Heywood and Hadley are two well-mannered people. This misunderstanding is largely due to the translator's failure in maintaining the speech features of the two. By omitting the two images, the translator reduces the amount of assumptions triggered in the two sentences thus reducing the relevance. So the audience cannot get adequate contextual effects to understand Haywood. Another choice is maintaining the original images in their Chinese version as "Never in my life seen such a heap of maggot" and "Carry the tub of shit to the treatment room". In this version, the relevance of the weakly conveyed assumptions triggered above is much stronger than the first version. However, this does not mean that it is a good-for-ever solution for all sentences with images. The last two sentences are cases in point. They are translated into "Which one shall you take" and "It's said you are ruthless" instead of their literal translation. How to explain this contradiction? The answer lies in the different cognitive environments of Americans and Chinese. In the former case, the images and associated impressions of "shit and maggot" are generally identical. The new stimulus into the shared cognitive environment allows Americans and Chinese to find the relevance easily. On the other hand, the concepts of horse and fish have different assumptions in the two cognitive environments. The relevance achieved in Americans might fail to do so in their Chinese counterparts. To Americans "Who's your horse?" brings about a series of assumptions around the activity of "horse race". By saying "It's said that you are ruthless" another Hollywood movie The Professional will be popped out in the minds of Chinese audience.

"Irony is a subtle form of humor, which involves saying things that you do not mean" (Collins Cobuild English Dictionary: 893). This humorous effect is achieved when contextual effects are adequate enough to convince the audience that the opposite of the literal meaning is what the author wants to convey. Extra-efforts are rewarded because the message expressed in irony is strengthened. Besides, the author's attitudes toward a certain character or a behavior are manifested. For example,

\section{Example 6.}

"grain \& drain" vacation. Bread, water, and all the privacy you could want.

You make your customers' motives a part of your business? English speakers can sense the irony in the above two sentences. Therefore, the recognition of the attitudes and emotions conveyed by the speaker is of vital importance in 
the interpretation process. Translator has to let the target audience appreciate the irony. Irony is likely to bring readers temporary understanding difficulties, which are expected to be extra-rewarding. So relevance theory demands translators to let target-language audience appreciate the irony, regardless of lingual and cultural obstacles. In the first sentence of Example 6, Red calls the punishment of confining prisoners in a windowless as "grain \& drain" vacation. It offers all the privacy you could want. A little confused, the audience might understand the implications later. In the movie, Andy is confined - the privacy here is confinement. The extra-efforts are rewarded with more contextual effects. Therefore this ironic feature of the script should be persevered instead of changing it into the straightforward statement so as to keep the optimal relevance of the original script.

The second sentence is Andy's response to Red's inquiry. Andy requires Red to get him a rock-hammer. Red thinks it is lethal, which might be used as weapon. We can sense Andy's antipathy by countering, "You make your customers' motives a part of your business?" The translator puts it straightforward as "Why you care it" to make Andy's response explicit. It seems to raise the relevance of the utterance. However, with less efforts needed in interpreting process, the reward is reduced at the same time. Andy, a vice-president of a bank before, is expected to be well educated and well mannered. What he says should fit his background and position. Besides, Andy was rather quiet in prison, trying to adjust himself to the life inside. It's the first time for Andy and Red to strike a conversation. He will not spoil his first attempt to have an intimate contact with the king there. So he is quite unlikely to use offensive words. But its Chinese version "Why you care it" seems a little offensive. In this sense, putting its Chinese version as "Is the buyer's intention part of your service?" might make more sense in the perspective of optimal relevance.

In the translation of irony, the tone of original text is of the most importance. Generally speaking, the ironic effects are achieved via the oppositions of meanings of its literal meaning. Therefore, literal translation will achieve the same effect in the target language circumstance. However, the explication of the irony without consideration of the context might not be acceptable. The tone and the way of expression should be preserved.

\subsubsection{Translation of Sentences with Slangs and Expressions}

The Shawshank Redemption is a movie portraying the prisoners' physical and mental states. The jail is operated by the greedy and bloody warden and captain. As victims, the prisoners are forced to keep their minds occupied, most of whom are institutionized, keeping busy dying. People there are slavery, having neither respect nor dignity. One of the themes of the movie is how hope and the desire of living a normal life free people. The inhumane conditions and torture make audiences sympathetic towards prisoners in Shawshank. The wordings of the prisoners in the movie are rather informal and full of slangs. See the table below.
Table 1. Slangs in the film.

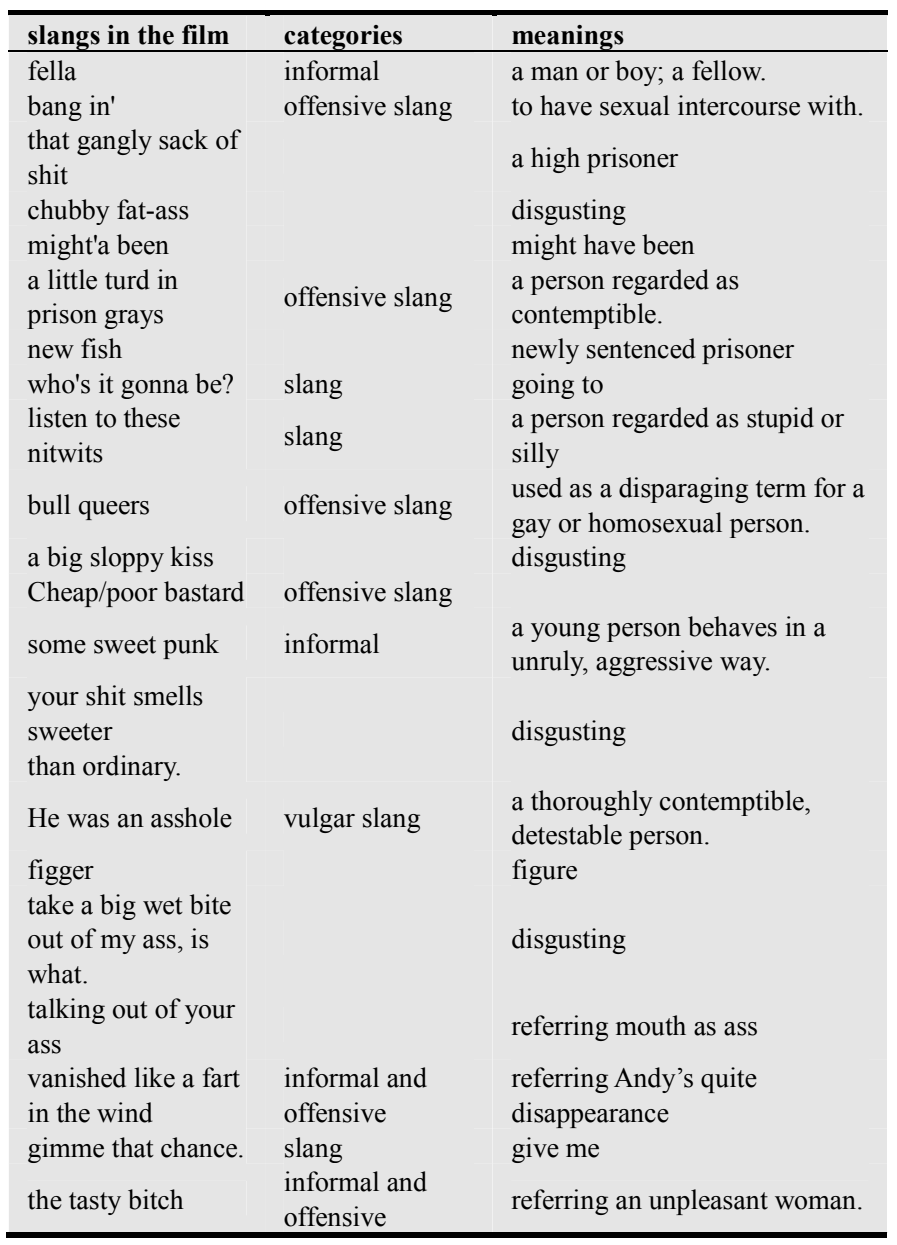

From the table above we can conclude that the words used by prisoners, warden and other police are very offensive. Features of the language in the movie are important to deliver the theme and characters. But in its Chinese version, all the offensive and vulgar expressions have been modified. The reasons behind might be many-fold. Chinese TV-series and movies employ comparatively less amount of the offensive expressions. So the ordinary audience finds it rather uncomfortable when such lines pop out. The other fear is that the general impression and the themes of the movie might be spoiled if its Chinese version keeps all the offensive expressions. Chinese audience might deny the film because of its offensive expressions. Out of these considerations, the translator changes the lines with more polished words. For someone, the change seems all right. The translator employs the synonyms of the original script in Chinese version, expecting to mean the same. However, there are different connotations between the words "statesman" and "politician". "The difference in connotation, on the other hand, would naturally be provided for by the fact that each word is mentally represented by a distinct concept, and that each of these concepts could have its own encyclopaedic entry" (Wilson \& Sperber, 2001: 162). The efforts made by reaching different encyclopaedic entries are different. For Chinese audiences, offensive expressions should be stored in the deep back of the minds, for they don't use offensive words often. When they 
make extra efforts to process the encyclopaedic entries, they are rewarded. They have better understanding of prisoners' social statues and the setting of the movie. In other words, the using of offensive and four-letter words will strengthen the characters and theme. "The lack of consideration of the features of characters, of the specific circumstances of particular characters is the main problem in scriptwriting" (Xia, 2004: 109). Once drop these features out, the relevance of the translated subtitles and the relevance between original and translated one are reduced. In this extent, the unpolished version should be reserved.

\subsection{Omissions in Movie-Subtitle Translation}

Film is a multimedia art form. Dialogues among characters are not the only method of unfolding films. Audio-visual means, together with the subtitles make the unfolding of a story smoother and more coherent. So the omission in translation is common. The following is the dialogue between Andy and Red.

Example 7.

RED: Got his fingers in a lot of pies, from what I hear.

ANDY: What you hear isn't half of it. He's got scams you haven't dreamed of. Kickbacks on his kickbacks. There's a river of dirty money flowing through this place.

RED: Money like that can be a problem. Sooner or later you gotta explain where it came from.

ANDY: That's where I come in. I channel it, funnel it, filter it... stocks, securities, tax free municipals... I send that money out into the big world. And when it comes back...

RED: It's clean as a virgin's whistle?

ANDY: Cleaner. By the time Norton retires, I will have made him a millionaire.

RED: Jesus. They ever catch on, he's gonna wind up wearing a number himself.

ANDY: (smiles) I thought you had more faith in me than that.

RED: I'm sure you're good, but all that paper leaves a trail. Anybody gets too curious -- FBI, IRS, whatever -- that trail's gonna lead to somebody.

ANDY: Sure it will. But not to me, and certainly not to the warden.

RED: Who then?

ANDY: Peter Stevens.

RED: Who?

ANDY: The silent, silent partner. He's the guilty one, your Honor. The man with the bank accounts. That's where the filtering process starts. They trace it back, all they're gonna find is him.

RED: Yeah, okay, but who the hell is he?

ANDY: A phantom. An apparition. Second cousin to Harvey the Rabbit. (off Red's look) I conjured him out of thin air. He doesn't exist... except on paper.

...

RED: Jesus. Did I say you were good? You're Rembrandt.

Warden Norton gets money from a contractor, who tucks the money in the pie. Red says "Got his fingers in a lot of pies, from what I hear." He means that Warden Norton takes undeserved money through his seemingly bright program. Due to the circumstances, it is not wise to speak out what he knows about candidly. "A kickback is a sum of money that is paid to someone illegally, for example money which a company pays someone to arrange for the company to be chosen to do an important job" (Collins Dictionary). Kickbacks on kickbacks might be an Andy-coined word suggesting that Norton gets dirty money as much as possible by any means. When learning what is going on, Red says "he gonna wind up wearing a number himself". It is a common sense that the prisoners are numbered when they start serving their terms. With this background, we can point out the real message behind-the police will arrest Norton. Fans of Hollywood's movie in China are familiar with FBI, but as for what is IRS, there is no ready answer. IRS "is abbreviation of Internal Revenue Service". The lack of this piece of information will block the understanding so the translator cannot leave IRS unchanged in Chinese version. Another problem arises out of the different titles of relatives. Second cousin is the child of one's first cousin (same as cousin), who is a child of one's aunt or uncle. Harvey the Rabbit, Oregon, is a 26-foot-tall mutant rabbit man. The statue lay abandoned at Harvey Marine for years (Harvey the Giant Rabbit). Rembrandt was a 17 th century painter and etcher whose work came to dominate what has since been named the Dutch Golden Age. One of the most revered artists of all time, Rembrandt's greatest creative triumphs are seen in his portraits of his contemporaries, illustrations of biblical scenes and self-portraits as well as his innovative etchings and use of shadow and light (Rembrandt Biography). Andy wants to convince Red that he is the master. He can make out an imaginary character with all the identifications one needs. Now we can grasp the core of the dialogue-Red is amazed at Norton's dirty money and Andy's genius for keeping fake accounts. Is it necessary to translate these sentences one by one? It is not hard to know that "Kickbacks on his kickbacks" and "There's a river of dirty money flowing through this place" can be combined. The money is dirty because it is kickbacks. So the translator produces its Chinese version as "Here comes the steady stream of black money". Another example is "I'm sure you're good, but all that paper leaves a trail. Anybody gets too curious --- FBI, IRS, whatever --- that trail's gonna lead to somebody". Its translation is "I know you're capable, but paper will leave a thread of a spider and trail of a horse. Once it was suspected... someone would be involved". The translation is idiomatic. We hardly can say there is any main point lost. In addition, taking the dialogue as a whole renders the translator more freedom in combining and simplifying the original text. The point is that the translator can achieve the similar relevance among Chinese audience. In other words, the amount of information processed is reduced while the context effects are not reduced accordingly.

However, it is not always proper to combine sentences with similar meanings. Take the second to last sentence of this dialogue for example. The translator combines the three sentences as "That is the man in my fantasy". If the two words "phantom" and "apparition" mean much the same, the phrase 
"second cousin to Harvey the Rabbit" is quite different. We can't put it as "he is someone in my fantasy, the cousin to Harvey" in its Chinese version. The second part of the sentence points out Peter Stevens has his relatives therefore can be traced by the police. It is in contrary with the original message. In other words, the extra information "second cousin to Harvey the Rabbit" is expected to strengthen the effect. But its literal Chinese version fails to do so. Admittedly, if the Chinese audience thinks this information is relevant, they will make efforts to pick up the information of Harvey, a name of a foreign man. However, this doesn't make sense in the setting. Then what left to do might be dropping this information. To achieve reasonable relevance to ordinary Chinese audience, the better version might be "He is the cousin of the statue on the square".

From the above analysis of a specific dialogue, we can see that omission often happens in movie subtitles. The scene and sound in movie can link the story without subtitles. Besides, the repetitive occurrence of the same meanings can be combined as one. However, in some cases, the repetition itself has its unique contextual effects, which cannot be ignored. In deal with omissions, the translator has to grasp all the information to get full understanding of the film. But it does not necessarily mean he has to translate all the words. "In subtitling, the speech act is always in focus; intention and effects are more important than isolated lexical elements" (Baker, 2004: 247). The subtitles translation should obey this principle, too.

\section{Conclusions}

By analysis of the subtitle translation of The Shawshank Redemption and the specific features of the film, we see how relevance theory helps the translator in producing his/her Chinese version, in terms of cultural difference and language features. As inter-lingual interpretation, the translation should be able to allow the target language audiences to receive adequate contextual effects with a minimal effort. It is of vital importance. With this idea in mind, translators can tackle the problem successfully in film subtitle translation, for translation, at the core, is a form of communication rather than a piece of material of cultural and linguistic study. Besides, the audio-visual features of films grant translators more freedom to combine similar information to make the interaction more concise and coherent. However, the paper is based on the analysis of one movie only, so the problems in movie subtitle translation might not all be presented in this paper. Therefore, taking films of various genres as a corpus to analyze deserves more attention.

\section{References}

[1] Asher, R. E. \& M. Y. Simpson. The Encyclopedia of Language and Linguistics Volume 2 [M]. Oxford: Pergamon Press, 1994.

[2] Baker, M. Routledge Encyclopedia of Translation Studies [M]. Shanghai: Shanghai Foreign Language Education Press, 2004.
[3] Bell, R. T. Translation and Translating: Theory and Practice [M]. Beijing: Foreign Language Teaching and Research Press, 2003.

[4] Behrens, Susan J \& Parker, Judith A. Language in the Real World: Introduction to Linguistics [M]. London: Routledge, 2010.

[5] Brown, G. \& George Yule. Discourse Analysis [M]. Cambridge: Cambridge University Press. Carter, R. (1997), 1983.

[6] Collins Cobuild English Dictionary [M]. Shanghai: Shanghai Foreign Language Education Press, 1999.

[7] Dick, F. B. Anatomy of Film, 2nd edn [M]. New York: St. Martin's Press, 1990.

[8] Hickey, L. The Pragmatics of Translation [M]. Shanghai: Shanghai Foreign Language Education Press, 2001.

[9] Gutt, E.-A. Translation and Relevance: Cognition and Context [M]. Shanghai: Shanghai Foreign Language Education Press, 2004.

[10] Katan David. Translating Cultures An Introduction for Translators, Interpreters and Mediators [M]. Shanghai: Shanghai Foreign Language Education Press, 2004.

[11] Luyken, Georg-Michael etal. (eds.). Overcoming Language Barriers in Television: Dubbing and Subtitling for the European Audience [M]. London: University of Luton Press, 1991.

[12] Morgan, David. 2015. "Shawshank Redemption," "Ghostbusters" added to National Film Registry. http://www.cbsnews.com/news/shawshank-redemption-ghostb usters-added-to-national-film-registry-2/.

[13] Newmark, P. A Textbook of Translation [M]. Shanghai: Shanghai Foreign Language Education Press, 2001.

[14] Sperber, D. and Wilson, D. Relevance: Communication and Cognition, 2nd edn [M]. Shanghai: Shanghai Foreign Language Education Press, 2001.

[15] Wilson, D. Relevance and Communication [J]. Modern Foreign Languages. 2000 (4): 210-217.

[16] Jin Di. Equivalent Translation [M]. Beijing: China Translation \& Publishing Corporation, 1998.

[17] Liu Miqing. Contemporary Studies of Translation [M]. Beijing: China Translation \& Publishing Corporation, 2003.

[18] Liu Miqing. English Varieties and Translation [M]. Beijing: China Translation \& Publishing Corporation, 1998.

[19] Lv Xu. Practical English Rhetoric [M]. Beijing: Tsinghua University Press, 2004.

[20] Lv Yuyong \& Li Min, Entertained Rewriting in the Film Subtitle Translation---with Men in Black III and Madagascar 3 : Europe's Most Wanted as the case study [J]. Chinese Translators Journa1. 2013 (3): 105-109.

[21] Zheng Baoxuan. Intra-lingual and Inter-lingualtranslation of Movie Subtitles [J]. Chinese Translators Journal. 2011(4): 75-78.

[22] Wang Hongyin. A Comprehensive Coursebook off English and Chinese Translation [M]. Daliang: Liaoning Normal University Press, 2002.

[23] Xia Ran. Issues in Film Scriptwriting [M]. Shanghai: Fudan University Press, 2004. 
[24] Harvey the Giant Rabbit http://www.roadsideamerica.com/story/2191.

[25] Kickback http://fanyi.baidu.com/?aldtype=85\#en/zh/kickback.

[26] Pronouncement of Marriage https://www.officianteric.com/pronouncement-of-marriage/.

${ }^{1}$ For the Chinese version of the film, refer to

http://wenku.baidu.com/link?url=bZdiOLLm9mbLH194q67XX1 ATVvMfGYnHMwNROI7fk g5JZE3m2s96-7RSn0hiO7y1AWOTUksvgoE1y6KHr6LjNz7R1TTQ2VXXYdL-zF4Jy7e
[27] Rembrandt http://www.biography.com/people/rembrandt-9455125.

[28] Reno divorce history http://renodivorcehistory.org/themes/law-of-the-land/.

[29] word-game. Dictionary.com Unabridged. Retrieved December 13, 2015 from Dictionary.com $\mathrm{http}: / /$ dictionary.reference.com/browse/word-game. 